ИЗВЕСТИЯ АКАДЕМИИ НАУК ЭСТОНСКОИ ССР. ТОМ 25 ХИМИЯ * ГЕОЛОГИЯ. 1976, № 4

Вайке ЛААН, Н. МАСПАНОВ, Рутт ТОМСОН, Татьяна ЛЕСМЕНТ, С. ФАЙГОЛЬД

\title{
КОЛЛОИДНО-ХИМИЧЕСКИЕ СВОЙТВА НЕКОТОРЫХ АЗОТСОДЕРЖАЩИХ ПОВЕРХНОСТНО-АКТИВНЫХ ВЕЩЕСТВ
}

Из поверхностно-активных веществ (ПАВ) наиболее перспективными являются азотсодержащие. Некоторые представители этого класса соединений известны давно, но применения не получили. В последние годы отмечено появление повышенного интереса к этим веществам $\left[{ }^{1-3}\right]$. Это связано, по-видимому, с тем, что они хорошие диспергаторы и могут служить основой для создания композиций моющих средств, в которых отсутствуют фосфаты. В данной работе исследованы четыре гомологических ряда амфолитных ПАВ (табл. 1).

Таблица 1

Синтез аминосодержащих ПАВ

\begin{tabular}{l|l}
\hline Вещество & Синтез \\
\hline
\end{tabular}

2-[1-метилалкиламино]этилсульфаты

$\mathrm{RCl}+\mathrm{NH}_{2} \mathrm{CH}_{2} \mathrm{CH}_{2} \mathrm{OH} \rightarrow$

$\rightarrow \mathrm{RNHCH}_{2} \mathrm{CH}_{2} \mathrm{OH} \stackrel{\mathrm{SO}_{3}}{\longrightarrow}$

2-[алкиламино]этилсульфаты

$\rightarrow \stackrel{+}{\mathrm{R}} \mathrm{H}_{2} \mathrm{CH}_{2} \mathrm{CH}_{2} \mathrm{OSO}_{3}^{-} \stackrel{\mathrm{NaOH}}{\longrightarrow}$

$\rightarrow \mathrm{RNHCH}_{2} \mathrm{CH}_{2} \mathrm{OSO}_{3} \mathrm{Na}$

2-[1-метилалкиламино]этансульфонаты $\mathrm{RCl}+\mathrm{NH}_{2} \mathrm{CH}_{2} \mathrm{CH}_{2} \mathrm{SO}_{3} \mathrm{Na} \rightarrow$

2-[алкиламино]этансульфонаты

$\rightarrow \mathrm{RNHCH}_{2} \mathrm{CH}_{2} \mathrm{SO}_{3} \mathrm{Na}$

Пр и ме ч а н и : $\mathrm{R}$ - алкил- или 1-метилалкилрадикал.

Исходным сырьем для получения указанных веществ являются вторичные и первичные хлоралканы. Соединения типа сульфатов получают в результате реакции присоединения хлоралканов к аминоспиртам и их производным с последующей сульфоэтерификацией по гидроксилу и нейтрализацией. Соединения типа сульфонатов получают присоединением хлоралканов к производным таурина. Исследовались гомологические ряды указанных веществ с числом углеродных атомов в алкильной цепи от 8 до 14 . 
Анализировались: зависимость поверхностного натяжения водных растворов от концентраций при статическом и динамическом режимах измерения, критические концентрации мицеллообразования, пенообразующая, смачивающая, эмульгирующая и моющая способности.

Для исследования поверхностного натяжения использовали сталагмометр с автоматическим счетом капель. Критические концентрации мицеллообразования (KКM) определяли по соответствующим изотермам поверхностного натяжения при двухминутном (KKM-1) и двухсекундном (ККМ-2) режимах измерения. Пенообразующую способность определяли по Росс-Майлсу [4]. Смачивание оценивали по высоте капиллярного поднятия растворов ПАВ по ткани с помощью усовершенствованного прибора для определения капиллярности ткани []. Эмульгирующую способность устанавливали в результате исследования стойкости эмульсии, получаемой при конденсации пара в вазелиновом масле в присутствии раствора ПАВ. Моющую способность определяли с помощью опытных стирок стандартно-загрязненной ткани на лабораторном лаундерометре при температурах $20,50,80^{\circ} \mathrm{C}$. Фотометрирование образцов ткани проводили лейкометром Цейса. Моющую способность вычисляли с применением формулы Кубелки-Мунка [ $\left.{ }^{4}\right]$.

Поверхностное натяжение. При сопоставлении результатов определения поверхностного натяжения выяснилось (табл. 2), что исследуемые сульфаты характеризуются закономерным снижением значения поверхностного натяжения в соответствии с увеличением длины углеводородного радикала как при динамическом, так и при статическом режимах измерения, если ПАВ при температуре и концентрации опыта растворимы. Для 2 -[1-метилтридециламино]этилсульфата натрия величина поверхностного натяжения снижается до $21 \partial u н \cdot c \mu^{-1}$ при $20^{\circ}$ и концентрации $0,125 \%$. Поверхностное натяжение растворов сульфонатов разветвленного строе-

Таблица 2

Поверхностное натяжение и критические концентрации мицеллообразования (KКМ) для растворов при $20^{\circ} \mathrm{C}$

\begin{tabular}{|c|c|c|c|c|c|c|c|}
\hline \multirow{3}{*}{ Вещество } & \multirow{3}{*}{$R$} & \multirow{2}{*}{\multicolumn{4}{|c|}{$\frac{\text { Поверхностное натяжение, } \partial u н \cdot \text {. }^{-1}}{\text { Концентрация раствора, } \%}$}} & \multicolumn{2}{|c|}{$\mathrm{KKM}, \%$} \\
\hline & & & & & & \multirow{2}{*}{ KKM-1 } & \multirow{2}{*}{ KKM-2 } \\
\hline & & 0,25 & 0,125 & 0,063 & 0,031 & & \\
\hline $\begin{array}{l}\text { 2-[1-метилалкиламино]- } \\
\text { этилсульфаты }\end{array}$ & $\begin{array}{r}8 \\
10 \\
12 \\
14\end{array}$ & $\begin{array}{l}57,5 \\
33,5 \\
25,7 \\
20,9\end{array}$ & $\begin{array}{l}64,0 \\
39,0 \\
26,8 \\
21,0\end{array}$ & $\begin{array}{l}67,0 \\
47,1 \\
31,5 \\
22,3\end{array}$ & $\begin{array}{l}68,8 \\
54,5 \\
36,7 \\
24,0\end{array}$ & $\begin{array}{l}0,73 \\
0,31 \\
0,12 \\
0,04\end{array}$ & $\begin{array}{l}0,80 \\
0,40 \\
0,16 \\
0,24\end{array}$ \\
\hline $\begin{array}{l}\text { 2-[1-метилалкиламино]- } \\
\text { этансульфонаты }\end{array}$ & $\begin{array}{r}8 \\
10 \\
12 \\
13\end{array}$ & $\begin{array}{l}24,0 \\
25,1 \\
22,8 \\
25,2\end{array}$ & $\begin{array}{l}24,2 \\
27,4 \\
23,5 \\
25,2\end{array}$ & $\begin{array}{l}27,5 \\
34,5 \\
24,1 \\
29,2\end{array}$ & $\begin{array}{l}35,5 \\
46,5 \\
25,3 \\
32,5\end{array}$ & $\begin{array}{l}0,07 \\
0,12 \\
0,02 \\
0,12\end{array}$ & $\begin{array}{l}0,26 \\
0,36 \\
0,29 \\
0,33\end{array}$ \\
\hline $\begin{array}{l}\text { 2-[алкиламино]- } \\
\text { этилсульфаты }\end{array}$ & $\begin{array}{r}8 \\
10 \\
12\end{array}$ & $\begin{array}{l}35,3 \\
27,0 \\
-\end{array}$ & $\begin{array}{l}42,0 \\
34,0 \\
38,0^{*}\end{array}$ & $\begin{array}{l}51,0 \\
41,0 \\
43,1^{*}\end{array}$ & $\begin{array}{l}58,6 \\
48,4 \\
-\end{array}$ & $\begin{array}{l}0,25 \\
0,24 \\
0,08^{*}\end{array}$ & $\begin{aligned}>0,25 \\
0,12^{*} \\
0,10^{*}\end{aligned}$ \\
\hline $\begin{array}{l}\text { 2-[алкиламино]- } \\
\text { этансульфонаты }\end{array}$ & $\begin{array}{r}8 \\
10 \\
12\end{array}$ & $\begin{array}{l}35,6 \\
23,3 \\
27,9^{*}\end{array}$ & $\begin{array}{l}44,4 \\
24,8 \\
33,4^{*}\end{array}$ & $\begin{array}{l}53,0 \\
27,4 \\
35,3^{*}\end{array}$ & $\begin{array}{l}57,0 \\
41,3 \\
49,5^{*}\end{array}$ & $\begin{array}{c}>0,5 \\
0,03 \\
-\end{array}$ & $\begin{array}{c}>0,5 \\
0,06 \\
-\end{array}$ \\
\hline
\end{tabular}
$50^{\circ} \mathrm{C}$.

П рим еч ан ие. $R$ - число углеродных атомов. * - определение проведено при 
ния достигает $23-27 \partial u н \cdot c \mu^{-1}$ при концентрации $0,125 \%$ и температуре $20^{\circ}$.

Критическая концентрация мицеллообразования (ККМ-1 и ККМ-2) у исследованных веществ снижается в соответствии с увеличением длины углеводородного радикала (табл. 2), при этом у низших гомологов юбласть KКМ у́же. Это указывает на то, что у высших гомологов по сравнению с низшими формирование адсорбционных слоев на границах раздела фаз затруднено в условиях динамического режима измерения поверхностного натяжения. У сульфатов KKM (KKM-1 и KKM-2) достигается при бо́льших концентрациях, чем у сульфонатов, а область ККМ ýже.

Пенообразующая способность. У соединений нормального строения пенообразование исследовали при $50^{\circ}$, у разветвленных - при $20^{\circ}$ (табл. 3). Исследования показали, что низшие сульфаты обладают пони-

Пенообразование при $0,125 \%$-ной и смачивание

Таблица 3 при $0,25 \%$-ной концентрациях растворов $\left(20^{\circ} \mathrm{C}\right)$

\begin{tabular}{|c|c|c|c|c|c|c|}
\hline \multirow{3}{*}{ Вещество } & \multirow{3}{*}{$R$} & \multicolumn{2}{|c|}{$\begin{array}{c}\text { Пенообразование, } \\
\text { мм }\end{array}$} & \multirow{2}{*}{\multicolumn{3}{|c|}{$\begin{array}{c}\text { Смачивание, мм } \\
\text { ительность смачивания, } \\
\text { мин }\end{array}$}} \\
\hline & & \multirow{2}{*}{$\begin{array}{l}\text { Началь- } \\
\text { ная } \\
\text { высота } \\
\text { столба, } \\
\text { мнм }\end{array}$} & \multirow{2}{*}{$\begin{array}{c}\text { Устойчн- } \\
\text { вость } \\
\text { пены, } \\
\%\end{array}$} & & & \\
\hline & & & & 1 & 4 & 16 \\
\hline $\begin{array}{l}\text { 2-[1-метилалкиламино]- } \\
\text { этилсульфаты }\end{array}$ & $\begin{array}{r}8 \\
10\end{array}$ & $\begin{array}{r}25 \\
157\end{array}$ & $\begin{array}{r}12 \\
3\end{array}$ & $\begin{array}{l}29 \\
25\end{array}$ & $\begin{array}{l}47 \\
45\end{array}$ & $\begin{array}{l}68 \\
64\end{array}$ \\
\hline $\begin{array}{l}\text { 2-[1-метилалкиламино] - } \\
\text { этансульфонаты }\end{array}$ & $\begin{array}{r}8 \\
10 \\
12 \\
13\end{array}$ & $\begin{array}{l}195 \\
172 \\
230 \\
235\end{array}$ & $\begin{array}{l}82 \\
83 \\
80 \\
73\end{array}$ & $\begin{array}{l}29 \\
28 \\
25 \\
20\end{array}$ & $\begin{array}{l}41 \\
46 \\
39 \\
33\end{array}$ & $\begin{array}{l}67 \\
74 \\
67 \\
62\end{array}$ \\
\hline \multirow[t]{2}{*}{$\begin{array}{l}\text { 2-[алкиламино] - } \\
\text { этилсульфаты }\end{array}$} & $\begin{array}{r}8 \\
10\end{array}$ & $\begin{array}{r}21 \\
196\end{array}$ & 24 & - & - & - \\
\hline & 12 & 246 & 86 & - & - & - \\
\hline $\begin{array}{l}\text { 2-[алкиламино] - } \\
\text { этансульфонаты }\end{array}$ & $\begin{array}{r}8 \\
10 \\
12\end{array}$ & $\begin{array}{l}162 \\
178 \\
254\end{array}$ & $\begin{array}{l}88 \\
83 \\
73\end{array}$ & $\frac{-}{-}$ & - & - \\
\hline
\end{tabular}

Пр и мечание. $R$ - число углеродных атомов.

женным пенообразованием и значительно уступают в этом отношении сульфонатам. Высшие сульфаты по пенообразующей способности несколько уступают высшим сульфонатам, но превосходят додецилбензолсульфонат натрия. Например, 2-[додециламино]этилсульфат натрия по пенообразующей способности в 1,2 раза превосходит додецилбензолсульфонат натрия при одинаковых их концентрациях. Пеноустойчивость для соединений нормального строения определяли через 5 мин и для разветвленных соединений через 8 мин после образования пены. Низшие сульфаты характеризуются небольшой пенообразуюшей способностью и пеноустойчивостью. Пенообразующая способность сульфатов нормального строения в воде стандартной жесткости примерно на $10 \%$ лучше, чем в дистиллированной воде.

Смачивающая способность. Исследования проводили при температуре $20^{\circ}$ (табл. 3). Из полученных для растворов 0,125\%-ной концентрации 
данных видно, что как у сульфатов, так и у сульфонатов наибольшей высотой капиллярного подъема обладают низшие гомологи.

Эмульгирующая способность. По эмульгирующей способности исследованные азотсодержащие соединения нормального строения превосхо-

Таблица 4

Эмульгирующая способность (при 0,25\%-ной концентрации) и моющая способность по отношению к моющей способности додецилбензолсульфоната натрия

\begin{tabular}{|c|c|c|c|c|c|c|c|}
\hline \multirow{2}{*}{ Вещество } & \multirow[b]{2}{*}{$R$} & \multicolumn{3}{|c|}{ Стойкость эмульсии, \% } & \multicolumn{3}{|c|}{ Моющая способность, \% } \\
\hline & & $\begin{array}{l}\text { через } \\
2 \text { мин }\end{array}$ & $\begin{array}{l}\text { через } \\
5 \mathrm{Muн}\end{array}$ & $\begin{array}{c}\text { через } \\
10 \text { мин }\end{array}$ & $20^{\circ} \mathrm{C}$ & $50^{\circ} \mathrm{C}$ & $80^{\circ} \mathrm{C}$ \\
\hline $\begin{array}{l}\text { 2-[1-метил- } \\
\text { алкиламино]- } \\
\text { этансуль- } \\
\text { фонаты }\end{array}$ & $\begin{array}{r}8 \\
10 \\
12 \\
13\end{array}$ & $\begin{array}{l}23,1 \\
23,1 \\
31,0 \\
25,9\end{array}$ & $\begin{array}{l}16,7 \\
18,4 \\
31,0 \\
25,9\end{array}$ & $\begin{array}{r}9,1 \\
16,7 \\
26,6 \\
23,1\end{array}$ & $\begin{array}{r}39,7 \\
97,4 \\
115,0 \\
124,5\end{array}$ & $\frac{-}{-}$ & $\begin{array}{r}65,2 \\
161,3 \\
208,0 \\
222,1\end{array}$ \\
\hline $\begin{array}{l}\text { 2-[алкил- } \\
\text { амино]этил- } \\
\text { сульфаты }\end{array}$ & $\begin{array}{r}8 \\
10 \\
12\end{array}$ & $\begin{array}{r}9,1 \\
60,0 \\
67,0\end{array}$ & $\begin{array}{r}9,1 \\
23,0 \\
33,7\end{array}$ & $\begin{array}{c}0 \\
16,6 \\
33,7\end{array}$ & $\begin{array}{r}45,7 \\
73,8 \\
100,1\end{array}$ & $\begin{array}{r}118,0 \\
84,0 \\
174,0\end{array}$ & $\begin{array}{l}72,3 \\
78,4 \\
-\end{array}$ \\
\hline $\begin{array}{l}\text { 2-[алкил- } \\
\text { амино] этан- } \\
\text { сульфонаты }\end{array}$ & $\begin{array}{r}8 \\
10 \\
12\end{array}$ & $\begin{array}{l}28,5 \\
23,0 \\
68,9\end{array}$ & $\begin{array}{l}23,0 \\
23,0 \\
47,3\end{array}$ & $\begin{array}{l}23,0 \\
16,8 \\
37,5\end{array}$ & $\begin{array}{r}46,0 \\
74,0 \\
104,0\end{array}$ & $\begin{array}{r}62,5 \\
104,0 \\
171,0\end{array}$ & $\begin{array}{r}80,6 \\
125,0 \\
204,0\end{array}$ \\
\hline
\end{tabular}

Пр и ме ч а и е. $R$ - число углеродных атомов.

дят разветвленные азотсодержащие соединения (табл. 4), при этом сульфонаты обладают бо́льшей эмульгирующей способностью, чем сульфаты. Для 2-[1-метилалкиламино]этилсульфатов способность эмульгировать вазелиновое масло не установлена.

Моющая способность исследованных ПАВ определялась по отношению к моющей способности додецилбензолсульфоната натрия, принятого за стандарт. Установлено, что в этом отношении (табл. 4) сульфонаты превосходят соответствующие сульфаты. У высших гомологов моющая способность выше, чем у низших, а также выше, чем у додецилбензолсульфоната натрия. Для 2-[1-метилдодециламино]этансульфоната натрия моющая способность при $20^{\circ}$ составляет $124,4 \%$, а при $80^{\circ}-222,0 \%$.

\section{Обсуждение результатов и выводы}

Сульфаты и сульфонаты алкиламиноэтиловых спиртов закономерно снижают поверхностное натяжение в зависимости от длины углеводородного радикала. Различия в значениях поверхностного натяжения у отдельных членов гомологического ряда исследованных сульфонатов разветвленного строения небольшие. Все они в достаточно высокой степени снижают поверхностное натяжение, если при концентрации и температуре опыта растворимы.

Установлено, что соединения типа 2-[1-метилалкиламино]этилсульфатов подвергаются гидролизу при стоянии и повышенной температуре.

На это указывают низкая моющая способность, небольшая устойчивость пены, отсутствие эмульгирующей способности растворов этих веществ.

У высших гомологов по сравнению с низшими возрастает моющая способность и снижается ККМ, повышается начальная высота столба 
пены, но снижаются поверхностное натяжение при статическом и динамическом режимах измерения, устойчивость пены и высота капиллярного подъема растворов исследуемых веществ по ткани.

Сульфонаты превосходят соответствующие сульфаты по моющей способности, по пенообразованию, однако у них более низкие ККМ. Высота капиллярного подъема по ткани у сульфатов и сульфонатов почти одинакова.

Если сравнить по поверхностно-активным свойствам исследуемые вещества нормального и разветвленного строения, то выясняется, что 2-[1-метилалкиламино]этансульфонаты по моющей способности в некоторой степени превосходят другие вещества, но по пенообразованию и эмульгированию уступают соединениям нормального строения. По степени снижения поверхностного натяжения оба ряда веществ близки.

На основе изложенного можно сделать вывод, что исследуемые высшие производные алкиламиноэтилсульфонатов являются высокоэффективными поверхностно-активными и моющими веществами, которые могут найти широкое применение в промышленности при создании моющих средств, в которых отсутствуют фосфаты.

\title{
Л И Т Е Р Т У Р А
}

1. Pitts P. M., Detergent Age, No. 2, 20, 22, 70 (1968).

2. Bitar L. S., S orgenti H., Пат. СШӒ,, кл. $260-513$, № 3,3, 388. 154.

3. Cahil1 J. A., Lincoln R. M., Mejers J. А., Пат. Франции, кл. С11д, № 1, 557. 528.

4. Р жехин В. П., С ер ге ев А. Г., Руководство по методам исследования, технохимическому контролю и учету производства в масложировой промышленности. Л., 1963.

5. Садов Ф..И., Соколова Н. М., Вильдт Е. О., Калинина К. Г., Корча ги н М. В., М а шецкий А. И., Ши кан о ва Н. А., Лабораторный практикум по курсу химической технологии волокнистых материалов. М., 1963.

\author{
Институт химии \\ Академии наук Эстонской ССР \\ Поступила в редакцию \\ 28/IV 1975
}

Vaike LAAN, N. MASPANOV, Rutt TOMSON, Tatjana LESMENT, S. FAINGOLD

\section{MŌNEDE LÄMMASTIKKU SISALDAVATE PINDAKTIIVSETE AINETE KOLLOIDKEEMILISED OMADUSED}

Uuriti nelja homoloogilisse ritta kuuluvate lämmastikku sisaldavate pindaktiivsete ainete struktuuri ja kolloidkeemiliste omaduste omavahelist sõltuvust. Uuritud ainetest osutusid kōige efektiivsemateks kõrgemad tauriinderivaadid.

Vaike LAAN, N. MASPANOV, Rutt TOMSON, Tatjana LESMENT, S. FAINGOLD

\section{COLLOID-CHEMICAL PROPERTIES OF SOME NITROGEN-CONTAINING SURFACTANTS}

Relation between the structure and colloid-chemical properties of four homologous series of surfactants containing nitrogen has been investigated. It has been shown that higher derivatives of taurine are effective surface-active substances. 